\title{
A RELAÇÃO CUSTO-EFETIVIDADE COMO CRITÉRIO PARA A CONCESSÃO JUDICIAL DE MEDICAMENTOS
}

\author{
Bruno Terra de Moraes*
}

\section{RESUMO}

A judicialização da saúde encontra-se disseminada no Judiciário. Trata-se de assunto delicado, por repercutir de forma determinante na dignidade da pessoa. Entretanto, não se pode perder de perspectiva o aspecto econômico da questão, por se tratar de dever de prestação pelo Estado. Verificando-se, quanto ao assunto, a coexistência de diversos interesses, necessário se faz propor critérios para que a apreciação dessas demandas pelo Judiciário não se dê de maneira inteiramente apartada dos parâmetros adotados pelo SUS na concessão de medicamentos. E a relação custo-efetividade, por ser um dos parâmetros adotados pelo SUS, deve ser observada pelo Judiciário.

Palavras-chave: Direitos sociais; Judicialização da saúde; Dignidade; Aspecto econômico; Relação custo-efetividade.

\section{THE COST-EFFECTIVENESS RELATIONSHIP AS A PARAMETER FOR THE JUDICIAL CONCESSION OF MEDICINES}

\begin{abstract}
Judicialization of health is widespread in the Judiciary. It is a sensitive matter, because there is a decisive impact on the dignity of the person. However, can't be ignored the economic aspect of the issue, because it is a duty of state provision. Because of the different interests, it is necessary to propose criteria so that the assessment of these demands by the Judiciary does not occur in a completely different way from the parameters adopted by the SUS in the concession of medicines. The cost-effectiveness ratio, being a parameter adopted by the SUS, must be observed by the Judiciary.
\end{abstract}

Keywords: Social rights; Judicialization of health. Dignity; Economic aspect; Costeffectiveness.

\footnotetext{
* Mestre e Doutorando em Direito Civil pela Universidade do Estado do Rio de Janeiro. Procurador do Estado do Rio de Janeiro lotado na Procuradoria de Serviços de Saúde. Endereço profissional: Rua do Carmo, n. ${ }^{\circ} 27$, Centro, CEP 20011-900, Rio de Janeiro. E-mail: bterramoraes@ gmail.com
} 


\section{INTRODUÇÃO}

A judicialização da saúde vem ganhando contornos alarmantes nos últimos anos. De acordo com o Relatório Justiça em Números 2017, referente ao ano base 2016, produzido pelo Conselho Nacional de Justiça, tramitaram na Justiça, no ano de 2016, ao menos 1.346.931 processos relativos à temática da saúde, tendo sido verificado um aumento de $1300 \%$ em sete anos (CIEGLINSKI, 2018).

O assunto é delicado, já que a saúde é dos fatores que mais repercutem na dignidade da pessoa. Não à toa, a Constituição disciplinou com minúcia o direito à saúde, conforme se percebe do seu Título VIII, Capítulo II, Seção II, sendo sua matriz o art. 196, o qual estabelece a saúde como um direito de todos e dever do Estado. ${ }^{1}$

Não obstante o protagonismo do aspecto humano relativo ao direito à saúde, não se deve negligenciar o aspecto econômico que envolve o tema, questão sempre relevante em se tratando de situações que demandam atuação prestacional do Estado. Isso não passou despercebido, por exemplo, à Minstra Carmen Lúcia, do Supremo Tribunal Federal, para quem, no que tange ao direito à saúde, “de um lado, está o princípio da dignidade da pessoa, que é o núcleo do direito contemporâneo e dos cuidados do Estado e, de outro, a questão de recursos econômico financeiros" (CIEGLINSKI, 2018). A afirmação demonstra que não se pode negligenciar o aspecto econômico-financeiro da judicialização. E não é para menos: de 2008 a 2015, os gastos com o cumprimento de decisões judiciais em matéria de saúde saltaram, no âmbito da União, de R\$ 70 milhões para R\$ 1 bilhão (FARIELLO, 2017). Em momentos de crise como a ora vivenciada no país e, em especial, no Estado do Rio de Janeiro, o aspecto econômico do tema se torna ainda mais candente.

Diante de cenário em que diversos aspectos coexistem e devem ser considerados, é importante propor soluções para que a apreciação pelo Judiciário do pedido de fornecimento de medicamentos não ocorra mediante lógica inteiramente apartada dos parâmetros que norteiam a concessão de fármacos no âmbito do SUS. Por mais que uma demanda seja individualmente ajuizada, o envolvimento de recursos públicos impõe que a sua apreciação leve em consideração contexto mais amplo. Isto porque cada decisão prolatada em processo individual terá, ao fim e

\footnotetext{
1 Art. 196. A saúde é direito de todos e dever do Estado, garantido mediante políticas sociais e econômicas que visem à redução do risco de doenças e outros agravos e ao acesso universal e igualitário às ações e serviços para sua promoção, proteção e recuperação.
} 
ao cabo, repercussão no orçamento destinado à saúde e, por conseguinte, gerará impacto na vida de todos aqueles que dependem dessa prestação estatal.

Dessa forma, cabe ao juiz analisar se o requerimento da parte se sustenta à luz dos critérios utilizados pelo SUS na escolha dos medicamentos a ele incorporados, sem que haja uma admissão acrítica da prescrição realizada pelo médico assistente. Somente em situações específicas e adequadamente fundamentadas poderão prevalecer critérios desconectados da política pública de saúde.

E a relação custo-efetividade é um dos critérios que balizam o SUS na decisão de incorporação de medicamentos na política pública de assistência farmacêutica. Trata-se de critério que leva em consideração o aspecto econômico que envolve a política pública de saúde. Desse modo, importante analisar se tal critério deve ser levado em consideração pelo juiz ao apreciar a demanda de fornecimento de fármacos. É o que se passa a realizar.

\section{A SAÚDE COMO UM DIREITO SOCIAL}

O direito à saúde se encontra, na Constituição, dentre aqueles denominados direitos fundamentais sociais, sendo mencionado já no seu art. 6. ${ }^{\circ 2}$. Importante notar que, por estar inserido no gênero direitos fundamentais, aplica-se à saúde o diposto no art. $5 .^{\circ}, \S 1 .^{\circ}$ da Constituição ${ }^{3}$, tendo, assim, aplicação imediata. Ressalte-se, ainda, que o referido art. $6 .^{0}$ corporifica uma cláusula pétrea, conforme art. 60, de modo que o direito a saúde não pode ser suprimido.

Mas nem sempre foi assim. Ao longo do Império e da República Velha, a prestação estatal do serviço de saúde era visto como uma simples benesse estatal, não constituindo, portanto, uma obrigação do Estado. Como benesse que era, não era exigível por parte dos seus potenciais beneficiários (ASENSI, 2012, p.2-3).

A fase seguinte teve início no governo de Getúlio Vargas. Ainda que de forma episódica, a Constituição de 1934 mencionou o direito à saúde em seu artigo 10, inciso II, ao

2 Art. 6. $^{\circ}$ São direitos sociais a educação, a saúde, a alimentação, o trabalho, a moradia, o transporte, o lazer, a segurança, a previdência social, a proteção à maternidade e à infância, a assistência aos desamparados, na forma desta Constituição.

3 Art. 5. ${ }^{\circ}$ Todos são iguais perante a lei, sem distinção de qualquer natureza, garantindo-se aos brasileiros e aos estrangeiros residentes no País a inviolabilidade do direito à vida, à liberdade, à igualdade, à segurança e à propriedade, nos termos seguintes:

$[\ldots]$

$\S 1 .^{\circ}$ As normas definidoras dos direitos e garantias fundamentais têm aplicação imediata. 
dispor sobre a competência concorrente entre União e Estados no que se refere à saúde e assistência públicas. E no seu artigo 121, § 1. ${ }^{\circ}$, h), a Constituição de 1934 definia que as assistências médica e sanitária do trabalhador e da gestante eram preceitos que a legislação trabalhista deveria seguir (DALLARI, 2012, p.87). Portanto, nota-se a estreita vinculação entre o direito à saúde e o trabalho, lógica esta que permaneceu mesmo após a revogação da Constituição de 1934, cerca de três anos após a sua promulgação. A assistência médicocurativa, assim, passou a ser direito dos trabalhadores formais, que para isso contribuíam. Ocorre que, se por um lado, os trabalhadores formais podiam gozar de tal direito, este não era estendido àqueles que estivessem à margem do trabalho formal (ASENSI, 2012, p.3). Não é difícil perceber o enorme contingente de pessoas que não eram abrangidas pelo sistema então vigente, mormente se considerada a informalidade nas relações de trabalho dos trabalhadores rurais em um Brasil muito menos urbanizado que o de hoje. ${ }^{4}$

Portanto, o sistema de saúde era desprovido do caráter da universalidade. Essa situação mereceu, a partir da década de 70, severas críticas, o que gerou o movimento da Reforma Sanitária, "cuja bandeira se concentrou na saúde como um direito de todos" (ASENSI, 2012, p.3.). Um intenso movimento popular emergiu por ocasião da redemocratização do Brasil, o que culminou com a introdução da Saúde, na Constituição de 1988, como um direito fundamental e dever do Estado. Desta forma, o direito à saúde se desvinculou da relação formal de trabalho, passando a ser um direito de todos.

O direito à saúde visa à concretização de alguns dos princípios mais basilares do ordenamento jurídico brasileiro, e "que dão base à teoria dos direitos sociais, tal como a dignidade da pessoa humana, o mínimo existencial em saúde, a vedação de retrocesso social e o dever de progresso em saúde” (SCHULZE; GEBRAN NETO, 2015. p.31.).

Por estar inserido na referida categoria de direitos sociais, sua fruição depende de uma prestação positiva do Estado. ${ }^{5}$ Em assim sendo, necessário se faz, para a efetivação da saúde, o dispêndio de vultosos recursos públicos. Disso resulta o relevante embate entre necessidade e possibilidade, isto é, a necessidade dos destinatários do direito à saúde e a possibilidade de sua

4 Em 1940, a taxa nacional de urbanização era de 31,24\%; já em 2010, a taxa de urbanização do Brasil era de 84,36\% (Disponível em: 〈goo.gl/Mvz7Rn>. Acesso em: 07 maio 2018).

5 Na lição de José Afonso da Silva (1997, p.277), entende-se os direitos sociais como "prestações positivas proporcionadas pelo Estado direta ou indiretamente, enunciadas em normas constitucionais, que possibilitam melhores condições de vida aos mais fracos, direitos que tendem a realizar a igualização de situações sociais desiguais". 
promoção por parte do Poder Público. Atento a essa característica dos direitos sociais, como o é a saúde, J.J. Gomes Canotilho (2015, p.19-20) assim afirma:

Os direitos sociais são caros, já o dissemos. Algumas prestações indispensáveis à efectivação desses direitos devem ser asseguradas pelos poderes públicos de forma gratuita ou tendencialmente gratuita. Ora, o Estado Social só pode desempenhar positivamente as suas tarefas de socialidade se se verificar [...]:

1) Provisões financeiras necessárias e suficientes, por parte dos cofres públicos, o que implica um sistema fiscal eficiente e capaz de assegurar e exercer relevante capacidade de coacção tributária;

2) Estrutura de despesa pública orientada para o financiamento dos serviços sociais (despesa social) e para investimentos produtivos (despesa produtiva);

3) Orçamento público equilibrado de forma a assegurar o controlo do défice das despesas públicas e evitar que um défice elevado tenha reflexos negativos na inflação e no valor da moeda [...].

Impossível, portanto, pensar-se em direitos sociais sem pensar em recursos orçamentários e financeiros para a consecução das atividades estatais que visam à concretizálos. E, invariavelmente, no entrechoque entre necessidades e possibilidades, nota-se que, enquanto aquelas tendem ao infinito, estas últimas são limitadas, gerando, assim, a noção de escassez. Como resultado, o administrador deve realizar determinadas escolhas, as quais, se por um lado, contemplam determinadas necessidades, de outro, deixam diversas a descoberto. Neste diapasão, vale transcrever a lição de Fernando Fróes Oliveira (2013, p.35), para quem: "Como os recursos são limitados, no sentido de que não bastam para a satisfação de todas as necessidades existentes, o administrador se vê obrigado a realizar algumas escolhas dramáticas em relação a quais serão os interesses contemplados".

Nota-se, pois, que é ínsita à noção de direitos sociais a consideração acerca dos recursos que serão necessários para a sua concretização. E se assim o é, encontra-se presente aí, por consequência, a noção de políticas públicas, as quais, pela sua própria natureza, pressupõem a exclusão, de sua abrangência, de parte dos seus potenciais beneficiários. Explicase: em se tratando de políticas públicas, e sendo inerente a elas uma relação de escassez no cotejo entre as necessidades e os recursos para atendê-las, enquanto algumas dessas necessidades serão atendidas, outras não o serão. Um exemplo, que foge da questão da saúde, mas é bastante ilustrativo do que se disse, é o dos benefícios previdenciários. O legislador estabelece condições para que um potencial beneficiário passe a recebê-lo. Sendo assim, ao mesmo tempo em que se concede o benefício a quem implementa as condições para tanto, todos os demais, que não preencherem as tais condições, deixarão de ser contemplados. 
A lógica, portanto, é cruel: a noção de políticas públicas implica que alguns sejam contemplados com determinada prestação estatal, enquanto outros não. São as denominadas escolhas trágicas. Ao falar sobre o financiamento da prestação da saúde, que se dá por intermédio da tributação, assim afirma Daniel Giotti de Paula (2012, p.191):

\footnotetext{
Por mais que se arrecade, certo é que as aspirações humanas são inalcançáveis. Todos queremos o melhor tratamento possível, o melhor medicamento, o melhor profissional à nossa disposição.

Essa necessidade humana deve ser contemplada pelo Estado? Aí reside a escolha trágica. É preciso conceber uma escolha racional prévia sobre quais limites da atuação estatal na prestação do serviço de saúde.
}

A escassez frente às demandas leva, portanto, à necessidade de concepção de políticas públicas, que implicam escolhas acerca do que será por elas contemplado e do que não o será. A racionalidade mencionada no trecho acima transcrito é que será o termômetro de juridicidade das escolhas realizadas.

E esse raciocínio atinente à racionalidade não se resumirá ao balizamento das escolhas estatais no momento de se estabelecer quais são as prestações a serem incorporadas às políticas públicas em saúde, mas, também, deverão balizar o julgador no momento em que julga demandas que versam sobre prestações em matéria de saúde.

\section{A INCORPORAÇÃo de TECNOLOGIAS AO SUS E A NOÇÃo dE CUSTO- EFETIVIDADE COMO FATOR DE RAZOABILIDADE E EFICIÊNCIA NA PRESTAÇÃO DE SERVIÇOS EM SAÚDE}

De acordo com algumas das premissas já estabelecidas no presente trabalho, a saúde, sendo um direito social, depende, para a sua concretização, de prestações estatais. Nesse sentido, indissociável dessa ideia será a questão do financiamento de tais prestações. Sendo relevante a análise do financiamento das prestações de saúde e, consequentemente da racionalidade dos recursos disponíveis, certo é que não devem ser concebidos modelos que, já na sua gênese, signifiquem desperdício de recursos. Nesse sentido, deve ser analisado o disposto no artigo 19-Q da Lei n. ${ }^{\circ} 8.080 / 90$, em particular o seu $\S 2 .^{\circ}$, o qual estipula os critérios a serem considerados para a incorporação de tecnologias no SUS. ${ }^{6}$

Art. 19-Q. A incorporação, a exclusão ou a alteração pelo SUS de novos medicamentos, produtos e
procedimentos, bem como a constituição ou a alteração de protocolo clínico ou de diretriz terapêutica, são Rev. de Biodireito e Direito dos Animais | e-ISSN: 2525-9695 | Porto Alegre | v. 4 | n. 2 | p. 39 - 58 | Jul/Dez. 2018 
Quanto ao caput, ele prevê a existência de um órgão técnico especializado de assessoramento do Ministério da Saúde, qual seja, a Comissão Nacional de Incorporação de Tecnologias no SUS-CONITEC.

No tocante aos aspectos a serem levados em consideração na análise da incorporação de determinada tecnologia, o $\S 1 .^{\circ}$ do referido dispositivo menciona "a eficácia, a acurácia, a efetividade e a segurança do medicamento, produto ou procedimento" objeto do processo de incorporação. Nota-se, portanto, que a lei foi expressa no sentido da necessidade de que a tecnologia a ser incorporada ao SUS apresente resultados positivos relevantes. Os referidos aspectos são atestados por meio da Medicina Baseada em evidências-MBE. É o que se nota do trecho abaixo:

\begin{abstract}
A MBE, portanto, não é apenas um nome ou rótulo que caracteriza a descoberta científica sobre moléstias, produtos, medicamentos ou tratamentos. Ela consiste numa técnica específica para atestar com maior grau de certeza a eficiência, efetividade e segurança dos produtos, tratamentos, medicamentos e exames que foram objeto de diversos estudos científicos, de modo que os verdadeiros progressos da pesquisa médica sejam transpostos para a prática (SCHULZE; GEBRAN NETO, 2015, p.215).
\end{abstract}

Dentre os aspectos a serem considerados, encontra-se a eficiência, critério esse intimamente ligado ao custo-efetividade. Segundo Clênio Schulze e Gebran Neto (2015, p.217), a eficiência equivale dizer "qual o custo de determinado tratamento/medicamento e o resultado que o mesmo apresenta comparado com outros tratamentos". Pode-se dizer, assim, que a relação custo-efetividade diz respeito à comparação entre o ganho qualitativo a ser agregado ao SUS com a incorporação da tecnologia e os custos necessários para tanto, em comparação com outros tratamentos. É o que se infere do trecho a seguir transcrito:

Em resumo, a Análise Custo - Efetividade (ACE), metodologia de síntese utilizada na elaboração de uma ATS, é uma avaliação microeconômica, constituindo uma análise comparativa de cursos alternativos de ação tanto em termos de custos como de consequências: a diferença de custos (custo incremental) é comparada com a diferença

atribuições do Ministério da Saúde, assessorado pela Comissão Nacional de Incorporação de Tecnologias no SUS.

$\S$ 1. ${ }^{\circ}$ A Comissão Nacional de Incorporação de Tecnologias no SUS, cuja composição e regimento são definidos em regulamento, contará com a participação de 1 (um) representante indicado pelo Conselho Nacional de Saúde e de 1 (um) representante, especialista na área, indicado pelo Conselho Federal de Medicina. § 2. ${ }^{\circ} \mathrm{O}$ relatório da Comissão Nacional de Incorporação de Tecnologias no SUS levará em consideração, necessariamente:

I - as evidências científicas sobre a eficácia, a acurácia, a efetividade e a segurança do medicamento, produto ou procedimento objeto do processo, acatadas pelo órgão competente para o registro ou a autorização de uso; II - a avaliação econômica comparativa dos benefícios e dos custos em relação às tecnologias já incorporadas, inclusive no que se refere aos atendimentos domiciliar, ambulatorial ou hospitalar, quando cabível.

Rev. de Biodireito e Direito dos Animais | e-ISSN: 2525-9695 | Porto Alegre | v. 4 | n. 2 | p. 39 - 58 | Jul/Dez. 2018 
de consequências na forma de razão entre a diferença de custos e a diferença de consequências. A ACE supõe uma escolha entre intervenções, assumindo a escassez de recursos. Na ACE em saúde, as consequências das alternativas de procedimentos ou programas sob comparação geralmente se referem a um único efeito de saúde de interesse (mortalidade ou morbidade, mas pode se referir a vários) que é atingido em diferentes graus pelas opções comparadas e é medido em unidades naturais, como número de mortes evitadas, número de anos de vida ganho, número de dias com incapacidade, número de partos prematuros evitados ou número de fraturas evitadas, sendo os custos das alternativas medidos em unidades monetárias (CANUTO, 2018, p.2.).

Ainda sobre o tema, para fins de melhor explicitar o seu significado, deve-se observar que a análise custo-efetividade deságua em:

uma medida denominada razão de custo-efetividade incremental (ICER, do inglês incremental cost-effectiveness ratio), expressa em custo adicional por um desfecho de saúde ganho, em geral, anos de vida, ajustados por qualidade [...] ou anos de vida salvos [...]. A ICER é calculada pela razão entre a diferença de custo e a diferença de efetividade de duas alternativas (x e y):

ICER $=\frac{\text { Custo alternativa } y-\text { Custo alternativa } y}{\text { Efetividade alternativa } x-\text { Efetividade alternativa } y}$

(PINTO; SANTOS; TRAJMAN, 2016, p.58-59).

A relação custo-efetividade é, portanto, um dos fatores decisivos na escolha do administrador para a incorporação ou não da tecnologia considerada, já que se presta a desvendar se o aumento de custos decorrente da aquisição de determinado medicamento é compensado pelo incremento qualitativo que esse produto proporciona.

Note-se que intimamente ligada à noção de eficiência se encontra a previsão contida no inciso II do $\S 2 .^{\circ}$ do art. 19-Q. Resta ainda mais evidente ali a noção de custo-efetividade, embora com uma redação mais genérica, já que utiliza o termo custo-benefício. Mas a ideia é basicamente a mesma da já explicitada: o benefício trazido pela incorporação da tecnologia, em comparação com as tecnologias já previamente incorporadas, deve compensar os custos necessários para tanto.

A necessidade de se levar em consideração tais fatores na incorporação ao SUS de determinada tecnologia é fundamental para que se vá ao encontro das noções de sistema, universalidade e integralidade da prestação de saúde, expressamente mencionadas no art. 198 da CRFB/88, particularmente em seu caput e no inciso II. ${ }^{7}$

7 “Art. 198. As ações e serviços públicos de saúde integram uma rede regionalizada e hierarquizada e constituem um sistema único, organizado de acordo com as seguintes diretrizes:

$[\ldots]$

Rev. de Biodireito e Direito dos Animais | e-ISSN: 2525-9695 | Porto Alegre | v. 4 | n. 2 | p. 39 - 58 | Jul/Dez. 2018 
Quanto à noção de sistema, esta pressupõe a existência de diversos elementos interconectados. São diversos os atores do Sistema Único de Saúde ${ }^{8}$, que exercem uma influência mútua. Dessa forma, a atuação de um desses autores repercute na atuação dos demais. Como exemplo ilustrativo disso, ainda que banal, pode ser citada a influência que um equipamento de saúde que presta um mau serviço exerce sobre o demais. Se determinado hospital não atende a contento a sua demanda, isso certamente pressionará outro equipamento de saúde, ao qual irão acorrer aqueles não atendidos pelo hospital deficiente.

Em se tratanto de sistema, incompatível com ele será a existência de redundâncias, a implicar desperdício de recursos. Afinal, atendendo-se à lógica de um sistema, se há um excesso de recursos destinados a determinado serviço, tal excesso redundará numa falta em outro setor. Daí a necessidade de a incorporação tecnológica no SUS depender, dentre outras, da análise de custo-efetividade. Isto porque eventual incorporação de medicamento que não passa pelo crivo do custo-efetividade implica a própria subversão da lógica do sistema, já que o excesso de recursos gastos nesse serviço importará em perda de recursos em outro campo.

E a verificação da relação custo-efetividade também se compatibiliza com a noção de universalidade, dizendo respeito essa: "ao reconhecimento da saúde enquanto um direito fundamental de todo e qualquer ser humano, cabendo ao Estado garantir as condições indispensáveis ao seu pleno exercício e o efetivo acesso à atenção e assistência de saúde em todos os níveis de complexidade" (ASENSI, 2012, p.11).

Nota-se que a universalidade possui, assim, dois aspectos, quais sejam: a) o quantitativo, já que qualquer ser humano é o titular do direito à saúde; e b) o aspecto qualitativo, já que a universalidade impõe a assistência à saúde em todos os níveis de complexidade, quais sejam, baixa, média e alta. Para que a universalidade seja adequadamente perseguida, deve-se incorporar ao SUS tecnologias que possuem a maior abrangência possível, quer quantitativa, quer qualitativamente.

Ignorar, no momento de se julgar uma demanda de saúde, os estudos de custoefetividade realizados pela CONITEC é, indubitavelmente, militar contra a pretendida universalidade do SUS. A concessão de um medicamento cuja análise da relação custo-

II - atendimento integral, com prioridade para as atividades preventivas, sem prejuízo dos serviços assistenciais;"

8 Quanto confirmando a existência de diversos atores e múltiplas atividades dentro de um sistema, assim afirma Felipe Dutra Asensi (2012, p.5): "O desenvolvimento do SUS tem evidenciado a diversidade de atores que compõem este campo e a forma pela qual a pluralidade de práticas por ele desenvolvidas tem contribuído para o seu amadurecimento [...]". 
efetividade tenha sido negativa traduz distorção do sistema, restringindo sua abrangência, já que contribui para a retirada de recursos da política pública de saúde estabelecida.

No que tange à integralidade, esta diz respeito às diferentes modalidades de assistência à saúde, isto é:

significa, originariamente, a garantia do fornecimento de um conjunto articulado e contínuo de ações e serviços preventivos, curativos e coletivos, exigidos para todos os níveis de complexidade de assistência. Desse modo, tal princípio engloba ações de promoção, proteção e recuperação da saúde (ASENSI, 2012, p.11).

O mesmo raciocínio utilizado com relação à universalidade se aplica à integralidade: o fornecimento de medicamentos sem levar em consideração a relação custo-efetividade é pressionar o sistema de saúde, dando-se ênfase a uma determinada modalidade de assistência à saúde em detrimento das demais.

Infere-se daí que ignorar o impacto econômico que determinada tecnologia acarreta sobre o SUS é contribuir para que não se atinjam os objetivos insculpidos na própria Constituição no que se refere à abrangência da prestação pública de saúde.

E o tema ganha relevo em momentos como o atual, de aguda crise financeira do Poder Público em suas diversas esferas, podendo-se citar como exemplo o Estado do Rio de Janeiro, que se viu na contingência de decretar estado de calamidade financeira, o que ocorreu por meio do Decreto n. ${ }^{\circ}$ 45.692, de 17 de junho de 2016, bem como de aderir ao Regime de Recuperação Fiscal previsto pela Lei Complementar n. ${ }^{\circ}$ 159/17.

\section{AS FALSAS NOVIDADES EM MATÉRIA DE SAÚdE E A NECESSIDADE DE RELATIVIZAÇÃO DAS PRESCRIÇÕES MÉDICAS}

A consideração da relação custo-efetividade ganha ainda mais relevância na medida em que a discussão se trava em ambiente no qual as aparências, não raro, enganam. Explica-se: em grande parte das vezes, a concepção de um novo medicamento pela indústria farmacêutica não agrega um efetivo ganho terapêutico. São os medicamentos denominados me-too. Nesse sentido:

A estratégia da indústria farmacêutica é a manutenção de um mercado lucrativo, produzindo medicamentos muito similares aos campeões de venda. No mercado americano e também no brasileiro estão à venda, por exemplo, seis tipos de estatinas (sinvastatina, lovastatina, pravastatina, fluvastatina, atorvastatina e rosuvastatina), 
usadas para a redução do colesterol, que são variantes da primeira estatina descoberta, a sinvastatina. Estas "novidades", com pequenas variações químicas entre si, também são conhecidos como me-too. Apesar de, na maioria dos casos, não agregarem ganho terapêutico ao tratamento com o medicamento lançado inicialmente, os medicamentos denominados me-too são anunciados por seus fabricantes como medicamentos novos. O grande investimento em marketing para essas "novidades" acaba conquistando muitos profissionais de saúde e consumidores, que passam a prescrever e utilizar esses medicamentos e, muito frequentemente, pressionam os sistemas de saúde para a sua incorporação (GAVA et al., 2010, p.3404).

Ou seja, o que é "vendido" como novidade, não acarreta grandes benefícios em comparação com os medicamentos já presentes no mercado. E um ponto a ser levado em consideração, conforme ressaltado no trecho acima transcrito, é o forte trabalho de marketing, que leva a que profissionais de saúde passem a prescrever tais medicamentos me-too como se fossem reais novidades do mercado, mas que, contudo, não trazem um ganho qualitativo significativo em comparação com os medicamentos anteriormente utilizados.

A ANVISA, a partir de 2004, ao apurar o preço que os medicamentos teriam no mercado, passou a levar em consideração os ganhos terapêuticos de tais produtos em comparação com os medicamentos já comercializados. Os números impressionam: de 2004 a 2009, mais de $80 \%$ dos novos medicamentos não representavam um ganho terapêutico relevante em relação aos medicamentos já presentes no mercado (GAVA et al., 2010, p.3410). Essas inovações que trazem benefícios meramente marginais são denominadas incrementais:

[...] as inovações incrementais, que surgem em abundância e a todo tempo, só são incorporadas ao SUS se oferecem preços competitivos, apliando a opção de ofertas tecnológicas sem impacto orçamentário incremental. É por isso que as demandas das empresas fabricantes são tão importantes para a Conitec e para qualquer agência de ATS. Somente elas, as empresas, podem decidir qual o desconto a ser dado ao governo no caso de incorporação do seu produto.

No entanto, toda essa redundância de inovação chega ao mercado em busca de um lugar ao sol. Os lançamentos costumam estar protegidos por patentes e ter preços elevados que raramente compensam os benefícios marginais que prometem. Suas vendas são impulsionadas por campanhas de marketing intensivas, dirigidas a prescritores e doentes, e, em alguns países como o Brasil, é fator que deflagra ações judiciais (PETRAMALE, 2017, p.237).

Outro exemplo de estratagema utilizado pela indústria farmacêutica para aumentar a demanda por seus produtos e, consequentemente, elevar os seus lucros é o de incentivar a utilização off label de seus medicamentos, isto é, a sua utilização para casos não previstos em bula. Casos de ações judiciais destinadas a coibir tal prática já ocorreram nos Estados Unidos. É o que se infere do trecho a seguir transcrito: 
Em 3 de setembro de 2009, jornais de todo o mundo noticiaram: 'Pfizer paga US\$2,3 bilhões em Acordo sobre Comercialização' - para usar o título do texto do New York Times escrito por Gardiner Harris, repórter que acompanha os movimentos na área da saúde. Como ela esclareceu, o pagamento foi 'o maior em um acordo de fraude em serviços de saúde e a maior multa da história em casos criminais'. E por que a Pfizer foi penalizada? Por ter se declarado culpada (antes de a investigação chegar ao fim) em ações em que ela mesma e a subsidiária Pharmacia \& Upjohn foram acusadas de realizar promoção ilegal de quatro medicamentos - inclusive o Bextra. O Bextra foi um dos antiinflamatórios retirados de circulação por causarem efeitos adversos não previstos pelo FDA, a agência que controla a comercialização de medicamentos nos EUA. Mas a ilegalidade cometida pela Pfizer e subsidiária não residia nesse problema do medicamento, mas sim na prática de propagandear o chamado uso off label junto a médicos e outros profissionais de saúde. Off label quer dizer: fora da bula. Ao autorizar a comercialização de uma droga, o FDA estabelece para que usos ela pode ser prescrita, que constam na bula (TEIXEIRA, 2009, p.733-734).

Essa conjunção de fatores, isto é, uma estratégia contumaz da indústria farmacêutica de "renovar" sem, de fato, renovar; um marketing agressivo dos fabricantes de medicamentos; e a permeabilidade dos profissionais de saúde a esta estratégia, com a possibilidade de passarem a prescrever os medicamentos me-too como se novos eles fossem, acaba gerando a necessidade de se relativizar a importância da prescrição médica como meio de prova para o fornecimento do produto pleiteado em juízo. Vale dizer: se, por um lado, a prescrição médica é necessária para o fornecimento do medicamento, certamente não é suficiente. Imperioso será robustecer o conjunto probatório para embasar o pedido de medicamentos.

Recentemente, o Superior Tribunal de Justiça avançou positivamente no que tange ao estabelecimento de parâmetros para a concessão de medicamentos via judicialização, ao julgar, em sede de recurso repetitivo, o Recurso Especial 1.657.156/RJ. ${ }^{9}$ No referido julgamento,

9 Ementa: “ADMINISTRATIVO. RECURSO ESPECIAL REPRESENTATIVO DE CONTROVÉRSIA.TEMA 106. JULGAMENTO SOB O RITO DO ART. 1.036 DO CPC/2015. FORNECIMENTO DE MEDICAMENTOS NÃO CONSTANTES DOS ATOS NORMATIVOS DO SUS. POSSIBILIDADE. CARÁTER EXCEPCIONAL. REQUISITOS CUMULATIVOS PARA O FORNECIMENTO.

1. Caso dos autos: A ora recorrida, conforme consta do receituário e do laudo médico (fls. 14-15, e-STJ), é portadora de glaucoma crônico bilateral (CID 440.1), necessitando fazer uso contínuo de medicamentos (colírios: azorga $5 \mathrm{ml}$, glaub $5 \mathrm{ml}$ e optive $15 \mathrm{ml}$ ), na forma prescrita por médico em atendimento pelo Sistema Único de Saúde - SUS. A Corte de origem entendeu que foi devidamente demonstrada a necessidade da ora recorrida em receber a medicação pleiteada, bem como a ausência de condições financeiras para aquisição dos medicamentos. 2. Alegações da recorrente: Destacou-se que a assistência farmacêutica estatal apenas pode ser prestada por intermédio da entrega de medicamentos prescritos em conformidade com os Protocolos Clínicos incorporados ao SUS ou, na hipótese de inexistência de protocolo, com o fornecimento de medicamentos constantes em listas editadas pelos entes públicos. Subsidiariamente, pede que seja reconhecida a possibilidade de substituição do medicamento pleiteado por outros já padronizados e disponibilizados. 3. Tese afetada: Obrigatoriedade do poder público de fornecer medicamentos não incorporados em atos normativos do SUS (Tema 106). Trata-se, portanto, exclusivamente do fornecimento de medicamento, previsto no inciso I do art. 19-M da Lei n. 8.080/1990, não se analisando os casos de outras alternativas terapêuticas. 4. TESE PARA FINS DO ART. 1.036 DO CPC/2015 A concessão dos medicamentos não incorporados em atos normativos do SUS exige a presença cumulativa dos seguintes requisitos: (i) Comprovação, por meio de laudo médico

Rev. de Biodireito e Direito dos Animais | e-ISSN: 2525-9695 | Porto Alegre | v. 4 | n. 2 | p. 39 - 58 | Jul/Dez. 2018 
restou determinado que se, de um lado, a falta de incorporação de determinado tratamento ao SUS não é um empecilho a que haja a sua concessão via processo judicial, por outro, não é qualquer pleito em juízo que deve ser deferido pelo juiz. As seguintes condições foram estabelecidas a respeito do fornecimento de medicamentos via processo judicial:

a) Comprovação, por meio de laudo médico fundamentado e circunstanciado expedido por médico que assiste o paciente, da imprescindibilidade ou necessidade do medicamento, assim como da ineficácia, para o tratamento da moléstia, dos fármacos fornecidos pelo SUS;

b) incapacidade financeira de arcar com o custo do medicamento prescrito; e

c) existência do medicamento na ANVISA.

Pode-se dizer que os critérios acima estabelecidos possuem, respectivamente, natureza técnica, econômica e sanitária. Em se tratando o critério técnico o mais relevante para o presente estudo, é a ele que se dará enfoque. É de se questionar, assim, qual o significado da referida condição que mais se coaduna com o ordenamento. Para tanto, há de se levar em consideração, em um primeiro momento, se a solicitação de inclusão ao SUS do medicamento pleiteado já passou pelo crivo da Comissão Nacional de Incorporação de Tecnologias no SUS-CONITEC, que é, no Brasil, a instância que realiza a Avaliação de Tecnologia em Saúde (ATS). Passam pelo seu crivo as solicitações de inclusão de tecnologias no SUS. Com relação à ATS, observase o seguinte:

\begin{abstract}
A ATS é processo fundamental para a saúde pública, visto que a incorporação de um novo produto ou medicamento nas listas públicas de dispensação tem efeito indutivo positivo, posto que milhares de prescritores em todo o território passarão a utilizá-lo, porque está incluído nos programas governamentais. Assim, além da comprovação de eficácia e segurança que, no caso brasileiro, a Anvisa exige, seu fabricante deve comprovar ainda que ele é custo-efetivo, que, em comparação a tratamentos já existentes para a mesma finalidade, o novo produto tem vantagens, seja porque tem o mesmo perfil de eficácia e segurança ou superior (mas custa menos e pode ser acessível a maior número de doentes), seja porque é substancialmente superior em eficácia, em segurança, ou em ambos, e o custo excedente compensa o investimento com ganhos significativos para a saúde (PETRAMALE, 2017, p.228).
\end{abstract}

fundamentado e circunstanciado expedido por médico que assiste o paciente, da imprescindibilidade ou necessidade do medicamento, assim como da ineficácia, para o tratamento da moléstia, dos fármacos fornecidos pelo SUS; (ii) incapacidade financeira de arcar com o custo do medicamento prescrito; (iii) existência de registro na ANVISA do medicamento. 5. Recurso especial do Estado do Rio de Janeiro não provido. Acórdão submetido à sistemática do art. 1.036 do CPC/2015." (Recurso Especial 1.657.156/RJ. Relator: Min. Benedito Gonçalves. Julgamento: 25/04/2018. Órgão julgador: Primeira Seção. Publicação: 04/05/2018) 
Portanto, passa pelo crivo da CONITEC a análise da relação custo-efetividade da incorporação de determinado medicamento ao SUS. E a leitura do trecho acima transcrito deixa entrever hipótese em que o medicamento, embora apresentando vantagens com relação às tecnologias já constantes do SUS, não é a ele incorporado em razão de o custo excedente não compensar os ganhos para a saúde. É, portanto, possível que tecnologia superior seja mantida fora do SUS pelo fato de os custos acarretados com a sua incorporação não serem compensados com o ganho de qualidade.

Diante do quadro demonstrado, em caso de determinado medicamento ter merecido um parecer negativo na CONITEC por inexistência de adequada relação custo-efetividade, a sua judicialização somente poderá conduzir a um resultado de procedência em situações muito particulares, nas quais seja cabalmente demonstrado, via prova robusta, a ineficácia específica da tecnologia já incorporada pelo SUS. Afinal, o crivo da CONITEC é válido para os cidadãos em geral. Conceder algo que contrarie tal parecer é colocar alguém em situação desigual. Somente a comprovação de uma condição específica do paciente que torne a tecnologia ineficaz no caso concreto é que poderá conduzir a uma eventual procedência do pedido judicializado.

Mas não é só: se é possível a negativa de inclusão ao SUS de determinada tecnologia superior, mas que apresente custos desproporcionais, é de se cogitar que alguém sustente que a defasagem qualitativa da tecnologia já incorporada implicaria, por si só, uma ineficácia, mesmo que relativa, do tratamento constante do SUS. Essa interpretação não será válida, na medida em que a alegação de ineficácia pela mera defasagem qualitativa, em tese, da tecnologia incorporada, também implica violação ao princípio da igualdade. Afinal, a desafagem da tecnologia incorporada é algo que atinge a todos. Isso somente será descaracterizado em casos específicos, nos quais se comprove que, com relação a alguém, concretamente, o tratamento oferecido pelo SUS é absolutamente ineficaz.

Veja-se, então, que a CONITEC faz uma análise da relação custo-efetividade de forma abstrata. E uma relação custo-efetividade negativa, abstratamente considerada, é motivo legítimo para a não inclusão ao SUS de determinada tecnologia. E isso porque, como já se disse, nem sempre as novas tecnologias implicam benefícios substanciais.

Essa decisão da CONITEC deve, então, ser prestigiada, até porque ela tem efeitos que se aplicam aos cidadãos em geral. Porém, a relação custo-efetividade apurada pela CONITEC de modo abstrato pode ser desconstituída quando há a demonstração da ineficácia absoluta, no caso concreto, do tratamento já incorporado. Nesse caso, a relação custo-efetvidade se inverte, 
passando de negativa a positiva, ou seja, o ganho relativo com a utilização do medicamento não incorporado passa a ser relevante.

Mas e nos casos em que o tratamento pretendido ainda não teve uma solicitação de inclusão submetida à CONITEC, isto é, e nos casos em que a relação custo-efetividade ainda não foi analisada no âmbito do referido órgão? Nesses casos, referida análise deverá ser realizada no âmbito do processo, mediante a comparação entre os efeitos acarretados pela tecnologia já incorporada ao SUS em relação àqueles produzidos pela tecnologia ainda não incorporada neste último.

Logicamente que ao juiz, por sua formação específica, não é dado realizar, por si só, a análise concreta da relação custo-efetividade do tratamento pleiteado. Porém, há instrumentos em sua mão que propiciam um refinamento da sua apreciação do pedido. Note-se que o Conselho Nacional de Justiça (CNJ) editou a Recomendação n. ${ }^{\circ}$ 31, de 30 de março de 2010, a qual resolveu o seguinte, no seu item I:

I. Recomendar aos Tribunais de Justiça dos Estados e aos Tribunais Regionais Federais que:

a) até dezembro de 2010 celebrem convênios que objetivem disponibilizar apoio técnico composto por médicos e farmacêuticos para auxiliar os magistrados na formação de um juízo de valor quanto à apreciação das questões clínicas apresentadas pelas partes das ações relativas à saúde, observadas as peculiaridades regionais;

b) orientem, através das suas corregedorias, aos magistrados vinculados, que: b.1) procurem instruir as ações, tanto quanto possível, com relatórios médicos, com descrição da doença, inclusive CID, contendo prescrição de medicamentos, com denominação genérica ou princípio ativo, produtos, órteses, próteses e insumos em geral, com posologia exata; [...]

No caso de o Tribunal já ter atendido à recomendação constante do item a) acima citado, a análise de eventual custo-efetividade do tratamento pleiteado se torna mais simples. Para tanto, é preciso que o apoio técnico do magistrado informe qual o ganho efetivo que se pretende com o medicamento pleiteado em relação ao medicamento incorporado ao SUS. O órgão técnico, portanto, deverá municiar o juiz com a informação relativa ao ganho comparativo do medicamento pleiteado em relação ao medicamento fornecido gratuitamente no SUS.

E a análise do órgão técnico auxiliar do juízo pode comportar dois aspectos, sendo o primeiro deles a análise comparativa em abstrato. Assim, o primeiro ponto a ser abordado pelo corpo técnico é a comparação de um medicamento em relação a outro com base na literatura médica. 
Já o segundo aspecto é a análise por parte do corpo técnico das questões concretas atinentes ao paciente. Isso se torna possível na medida em que a petição inicial, invariavelmente, vem acompanhada de um laudo médico, que deve conter a descrição das condições específicas do autor. O órgão técnico, por conseguinte, fará o comparativo do medicamento pleiteado em relação àquele incorporado pelo SUS, mas, agora, levando em consideração as condições específicas do autor mencionadas na documentação que instrui o pedido inicial. Importante salientar que ao corpo técnico auxiliar do juízo será possível solicitar que o juiz intime a parte a complementar as informações constantes do seu laudo médico, caso seja necessário.

Além dos dois aspectos primordiais acima mencionados, esses relativos à parte técnica, útil para a verificação da relação custo-efetividade será o comparativo do preço do tratamento entre o medicamento pleiteado e o incorporado ao SUS.

O juiz, analisando todos os aspectos mencionados, chegará à conclusão acerca da relação custo-efetividade. Desse modo, verificará, com base nos dados informados pelo corpo técnico, se o ganho comparativo entre os medicamentos pleiteado e incorporado ao SUS compensa o aumento no custo.

E mesmo nos locais em que não foi implantado corpo técnico auxiliar do juízo é possível que se levem aos autos informações atinentes à comparação entre os medicamentos pleiteado e o fornecido pelo SUS. Não se pretende que o médico assistente da parte realize uma coleta aprofundada de dados para a verificação da relação custo-efetividade, até porque isso demanda técnicas de pesquisa e tempo, já que estudos especializados devem ser consultados para se obter os dados necessários à aferição daquela relação. Porém, está ao alcance de qualquer médico expor as razões pelas quais o medicamento $\mathrm{X}$, e não o $\mathrm{Y}$, foi prescrito. Com base nessas informações, o juiz verificará se existe uma exclusão absoluta da alternativa terapêutica fornecida pelo poder público. Se houver justificativas razoáveis e seguras da exclusão absoluta do medicamento fornecido pelo SUS, a decisão do juiz poderá se basear nos laudos médicos apresentados. Afinal, nesses casos de exclusão, como já se afirmou anteriormente, a escolha do medicamento não incorporado ao SUS significa a única possibilidade.

Entretanto, se, pelos laudos, não for possível aferir, de plano, uma vantagem comparativa relevante entre o medicamento pleiteado e aquele fornecido pelo SUS, o juiz deve determinar a realização de perícia para, aí sim, o perito realizar o trabalho de verificação da relação custo-efetividade entre os medicamentos considerados.

Rev. de Biodireito e Direito dos Animais | e-ISSN: 2525-9695 | Porto Alegre | v. 4 | n. 2 | p. 39 - 58 | Jul/Dez. 2018 
Evidentemente, se for verificado concretamente que é muito grande a quantidade de processos nos quais a perícia seria cabível, de modo a trazer embaraços à atividade jurisdicional e banalização da prova pericial, pode-se estabelecer, como medida pragmática, um parâmetro de valor a partir do qual a perícia deverá ser realizada. Assim, a perícia seria realizada, apenas, nos casos de impacto financeiro significativo do tratamento pleiteado.

Uma vez realizada a aferição da relação custo-efetividade - seja pela CONITEC, pelo corpo técnico de apoio ou por perito - deverá o juiz considerar tal dado no momento de julgar a demanda.

\section{CONCLUSÃO}

O direito à saúde foi alçado a uma posição de destaque no ordenamento jurídico brasileiro, merecendo expressa menção na Constituição, em particular nos seus arts. $6 .^{\circ}, 196$ e seguintes. Nos últimos tempos, a importância conferida ao direito à saúde no ordenamento se refletiu na expressiva judicialização do tema, por meio da qual se pretende concretizar o referido direito.

Tratando-se de um direito social, o direito à saúde, para ser concretizado, depende de dispêndio significativo de recursos. Portanto, aos gastos com as políticas públicas de saúde estabelecidas pelo poder público são agregados os gastos realizados para o cumprimento das decisões judiciais. A fonte de recursos, portanto, é a mesma, e os valores despendidos com o cumprimento das decisões judiciais não poderão ser utilizados nas políticas públicas estabelecidas.

Os gastos realizados no estabelecimento de políticas públicas pelo administrador e aqueles realizados para o cumprimento de decisões judiciais se encontram no mesmo contexto, razão pela qual uma demanda individual impacta o sistema como um todo. Ignorar isso implica pressionar o SUS, gerando distorções. Se os recursos destinados às políticas públicas de saúde e ao cumprimento das decisões judiciais provêm da mesma origem, ao decidir determinada demanda individual de saúde, não pode o juiz da causa negligenciar princípios e parâmetros utilizados pelo SUS para a incorporação de medicamentos. Pretende-se, dessa forma, minimizar aquelas distorções.

A relação custo-efetividade é um dos critérios utilizados pelo poder público na avaliação da incorporação ou não de determinado medicamento ao SUS. A decisão de fornecer ou não gratuitamente determinado medicamento passa por aquela análise da sua relação custo-

Rev. de Biodireito e Direito dos Animais | e-ISSN: 2525-9695 | Porto Alegre | v. 4 | n. 2 | p. 39 - 58 | Jul/Dez. 2018 
efetividade, o que implica verificar se o acréscimo de custos com a aquisição de tal medicamento é compensado com o ganho qualitativo obtido com a sua utilização no tratamento. Trata-se de verificação que contempla os aspectos técnico e econômico. E essa análise se torna ainda mais relevante na medida em que, como se demonstrou, nem sempre um novo medicamento implica um efetivo ganho terapêutico em relação ao medicamento mais antigo.

Desse modo, devendo o juiz considerar a relação custo-efetividade referentes ao medicamento pleiteado, importante verificar, antes de tudo, se a CONITEC já realizou tal estudo. Em caso negativo, pode o juiz lançar mão do corpo técnico auxiliar instituído no âmbito do tribunal respectivo. E mesmo que ainda não haja corpo técnico instituído no tribunal considerado, é possível que a análise seja realizada no processo via prova pericial, ao menos nos processos que tenham um significativo impacto financeiro.

\section{REFERÊNCIAS}

ASENSI, Felipe Dutra. O direito à saúde no Brasil. In: ASENSI, Felipe Dutra; PINHEIRO, Roseni (Org.). Direito sanitário. Rio de Janeiro: Elsevier, 2012. p.2-26.

BRASIL. Constituição da República dos Estados Unidos do Brasil (de 16 de julho de 1934). Disponível em: 〈goo.gl/xxoUgq>. Acesso em: 29 jul. 2018.

BRASIL. Constituição da República Federativa do Brasil de 1988. Disponível em: <goo.gl/yGpkAx>. Acesso em: Acesso em: 29 jul. 2018.

BRASIL. Lei n. ${ }^{\circ} 8.080$, de 19 de setembro de 1990. Dispõe sobre as condições para a promoção, proteção e recuperação da saúde, a organização e o funcionamento dos serviços correspondentes e dá outras providências. Disponível em: 〈goo.gl/MYtVAR>. Acesso em: Acesso em: 29 jul. 2018.

BRASIL. Lei Complementar n. ${ }^{0}$ 159, de 19 de maio de 2017. Institui o Regime de Recuperação Fiscal dos Estados e do Distrito Federal e altera as Leis Complementares n. ${ }^{\circ} 101$, de 4 de maio de 2000, e n. ${ }^{\circ} 156$, de 28 de dezembro de 2016. Disponível em: 〈goo.gl/BpQHMe〉. Acesso em: 29 jul. 2018.

BRASIL. Superior Tribunal de Justiça. Recurso Especial 1.657.156/RJ. Relator: Min. Benedito Gonçalves. Julgamento: 25/04/2018. Órgão julgador: Primeira Seção. Publicação: 04/05/2018.

CANOTILHO, J. J. Gomes. O direito constitucional como ciência de direção: o núcleo essencial de prestações sociais ou a localização incerta da socialidade (contributo para a reabilitação da força normativa da constituição social. In: CANOTILHO, J.J. Gomes; CORREIA, Marcus Orione Gonçalves; CORREIA, Érica Paula Barcha (Coord.). Direitos fundamentais sociais. 2.ed. São Paulo: Saraiva, 2015. p.11-31. 
CANUTO, Vânia. Avaliação econômica de tecnologias em saúde e limite custo-efetividade. Disponível em: <goo.gl/MSr8pU>. Acesso em: 06 jun. 2018.

CIEGLINSKI, Thaís. Judicialização da saúde: iniciativas do CNJ são destacadas em seminário no STJ. Conselho Nacional de Justiça, 22 maio 2018. Disponível em: 〈goo.gl/2AJqYu〉. Acesso em: 26 jul. 2018.

CONSELHO NACIONAL DE JUSTIÇA (CNJ). Recomendação n. ${ }^{\circ}$ 31, de 30 de março de 2010. Recomenda aos Tribunais a adoção de medidas visando a melhor subsidiar os magistrados e demais operadores do direito, para assegurar maior eficiência na solução das demandas judiciais envolvendo a assistência à saúde. Disponível em: 〈goo.gl/91mmo1〉. Acesso em: Acesso em: 29 jul. 2018.

DALLARI, Sueli Gandolfi. Direito constitucional à saúde. In: ASENSI, Felipe Dutra; PINHEIRO, Roseni (Org.). Direito sanitário. Rio de Janeiro: Elsevier, 2012. p.80-98.

FARIELLO, Luiza. TCU e Estados apontam aumento dos gastos com a judicialização da saúde. Conselho Nacional de Justiça, 11 dez. 2017. Disponível em: 〈goo.gl/1PW1qM>. Acesso em: 26 jul. 2018.

GAVA, Cíntia Maria; BERMUDEZ, Jorge Antonio Zepeda; PEPE, Vera Lúcuia Edais; REIS, André Luiz Almeida dos Reis. Novos medicamentos registrados no Brasil: podem ser considerados como avanço terapêutico? Ciência \& Saúde Coletiva, v.15, Supl. 3, p.34033412, 2010. Disponível em: <goo.gl/pJMHoQ>. Acesso em: 22 maio 2018.

INSTITUTO BRASILEIRO DE GEOGRAFIA E ESTATÍSTICA (IBGE). Séries históricas e estatísticas. Disponível em: 〈goo.gl/Mvz7Rn>. Acesso em: 07 maio 2018.

OLIVEIRA, Fernando Oliveira. Direitos sociais, mínimo existencial e democracia deliberativa. Rio de Janeiro: Lumen Juris, 2013.

PAULA, Daniel Giotti. Direito à saúde e finanças públicas: uma questão “trágica”. In: ASENSI, Felipe Dutra; PINHEIRO, Roseni (Org.). Direito sanitário. Rio de Janeiro: Elsevier, 2012. p.182-209.

PETRAMALE, Clarice. A comissão nacional de incorporação de tecnologias em saúde do SUSCONITEC: seu processo de trabalho, fluxos, desafios e oportunidades. In: NETO, João Paulo Gebran; AVANZA, Clenir Sani; SCHULMAN, Gabriel (Org.). Direito da saúde em perspectiva: judicialização, gestão e acesso, Vitória: ABRAGES, 2017. v.2. p.227-245.

PINTO, Márcia; SANTOS, Marisa; TRAJMAN, Anete. Limiar de custo-efetividade: uma necessidade para o Brasil. Jornal Brasileiro de Economia da Saúde, v.8, n.1, p.58-60, 2016. Disponível em: 〈goo.gl/YHHjmF>. Acesso em: 25 jul. 2018.

RIO DE JANEIRO. Decreto n. ${ }^{\circ}$ 45.692, de 17 de junho de 2016. Decreta estado de calamidade pública, no âmbito da administração financeira do Estado do Rio de Janeiro, e dá outras providências. Disponível em: 〈goo.gl/ZirCfV>. Acesso em: 29 jul. 2018.

SCHULZE, Clenio Jair; GEBRAN NETO, João Pedro. Direito à saúde: análise à luz da judicialização. Porto Alegre: Verbo Jurídico, 2015. 
SILVA, José Afonso. Curso de direito constitucional positivo. 13.ed. São Paulo: Malheiros, 1997.

TEIXEIRA, Mônica. A bilionária indústria da educação médica continuada nos EUA: mais uma forma de interferência das empresas na relação médico-paciente. Revista Latinoamericana de Psicopatologia Fundamental, São Paulo, v.12, n.4, p.731-742, dez. 2009. Disponível em: <goo.gl/AjjDES>. Acesso em: 22 maio 2018. 